07

\title{
Ионное сопротивление наноструктурированного электрохимического электрода в неравновесных условиях
}

\author{
(C) А.А. Нечитайлов, Н.В. Глебова, А.А. Томасов, А.О. Краснова, \\ Н.К. Зеленина
}

Физико-технический институт им. А.Ф. Иоффре РАН,

E-mail: Aan.shuv@mail.ioffe.ru

Поступило в Редакцию 9 апреля 2018 г.

Методами вольт-амперных характеристик, спектроскопии электрохимического импеданса и моделирования годографа импеданса исследовано in situ ионное сопротивление мембранно-электродных блоков $\mathrm{O}_{2} / \mathrm{H}_{2}$ топливного элемента с электродами, содержащими наночастицы платины на углеродной саже, углеродные нановолокна и протонпроводящий полимер Nafion в широком диапазоне составов. Исследован и предложен механизм возникновения неоднородностей и аномального увеличения ионного сопротивления при увеличении содержания Nafion в электроде.

DOI: $10.21883 /$ PJTF.2018.23.47019.17324

Транспортные свойства топливных элементов являются одним из важных факторов, определяющих их эффективность [1]. Зарядовый транспорт в электродах этих структур, содержащих протонпроводящий полимер типа Nafion и металлоуглеродный компонент $(\mathrm{Pt} / \mathrm{C})$, обычно лимитирован транспортом протонов, так как ионная проводимость Nafion на несколько порядков меныше электронной проводимости углеродной сажи [2]. Поскольку Nafion является не единственным компонентом электрода и увеличение его доли влечет уменьшение пористости и площади доступной поверхности платины [3], одной из задач при разработке электрода является оптимизация его компонентного состава, в частности содержания Nafion, с тем, чтобы была обеспечена хорошая газопроницаемость (массовый транспорт) при относительно небольшом ионном сопротивлении. В наших предыдущих исследованиях обнаружена аномальная зависимость ионного сопротивления от 
содержания Nafion. При увеличении содержания Nafion выше 40 wt.\% ионное сопротивление увеличивается.

Цель настоящей работы заключается в выяснении возможных причин этого явления.

В мембранно-электродном блоке (МЭБ) в условиях генерации и протекания электрического тока имеют место следующие массовые и зарядовые потоки: молекулярный кислород и водород диффундируют из приэлектродного объема в пористый катод и анод с образованием воды и гидратированных протонов и электронов соответственно; гидратированные протоны перемещаются через влажную мембрану (Nafion) на катод.

Распределение воды в системе зависит от многих факторов, наиболее значимыми из которых являются плотность тока, пористость и гидрофильность электродов [4-8]. Также на влажность анода влияет перенос воды протонами с анода через мембрану [4] в противовес диффузии на анод воды, возникающей в результате электрохимической реакции на катоде. Кроме того, повышенная температура в зоне реакции способствует уносу воды рабочими газами и возникновению градиента концентрации воды в районе прикатодной области.

При относительно небольших поляризациях в области вольтамперной характеристики (BAX) при отсутствии диффузионных ограничений концентрация кислорода и выделение воды практически одинаковы по толщине катода. При этом концентрационный профиль воды в катоде будет иметь максимум в толще электрода. При больших поляризациях и соответственно существенных диффузионных ограничениях [8] область выделения воды смещается к поверхности электрода. В соответствии с этим даже при условии однородности исходного состава электродов в них могут возникать неоднородности свойств в процессе генерации электрического тока.

Наиболее значимым явлением в этом случае можно считать неоднородность ионного сопротивления, связанную с неоднородностями влажности и температуры, так как ионное сопротивление Nafion зависит от влажности и температуры $[9,10]$.

При относительно большой доле центров генерации электрического тока (и соответственно воды), т.е. когда при большой доле активной платины в материале электрода количество уносимой с продуваемыми газами воды меньше выделяемой в результате электрохимической реакции, имеет место положительный баланс по воде [11]. В обратном

Письма в ЖТФ, 2018, том 44, вып. 23 
случае (небольшая доля активной платины в электроде) имеет место отрицательный баланс по воде, и влажность МЭБ поддерживается за счет влажности продуваемых газов и находится на более низком уровне. Необходимо отметить, что влажность Nafion, находящегося в равновесии, например, с кислородом со 100\% относительной влажностью, не достигает его предельной возможной влажности (влагосодержание около 22 молекул $\mathrm{H}_{2} \mathrm{O}$ на одну группу $\left.-\mathrm{SO}_{3} \mathrm{H}\right)$, и соответственно его ионное сопротивление примерно в 3-5 раз выше, чем для полностью гидратированного Nafion $[12,13]$.

Таким образом, при небольшом количестве центров генерации воды (частиц активной платины) неоднородность влажности при ее недостатке вызывает неоднородность и увеличение ионного сопротивления.

Имеется ряд работ, посвященных определению ионного сопротивления электродов МЭБ на основе анализа высокочастотной части годографа импеданса и моделированию различных случаев неоднородностей катода (см., например, [14] и [15] соответственно), но без объяснения природы неоднородностей.

В настоящей работе исследована серия МЭБ системы $\mathrm{Pt} / \mathrm{C}-\mathrm{УHB}-\mathrm{Nafion}$ (УНВ - углеродные нановолокна) различного компонентного состава с площадью электродов $1 \times 1 \mathrm{~cm}^{2}$. Компонентный состав менялся таким образом, чтобы получить образцы с различной долей платины и Nafion (см. таблицу).

При изготовлении МЭБ использовались многостенные углеродные нановолокна типа Таунит МД [16], платинированная углеродная сажа с массовым содержанием платины 40\% (коммерческий продукт марки E-TEK) и коммерческий раствор Nafion.

Формирование электродов проводилось способом, предусматривающим предварительное коагулирование Nafion из его раствора в жидкой фазе [17]. Метод изготовления МЭБ и измерение его пористости описаны в работе [18].

После изготовления проводилась активация МЭБ до стабилизации BAX [19]. При измерениях ВАХ, импеданса и площади электрохимически активной платины использовались стандартные методики [8] и приборы в среде кислород/водород при атмосферном давлении, температуре $\sim 23^{\circ} \mathrm{C}$ и относительной влажности газов $>90 \%$. Ионное сопротивление вычислялось по наклону линейного участка ВАХ, как в [18].

Годограф импеданса регистрировался непосредственно после регистрации BAX в тех же условиях $\left(\mathrm{O}_{2} / \mathrm{H}_{2}\right)$ при напряжении, близком

Письма в ЖТФ, 2018, том 44, вып. 23 
Характеристики исследуемых МЭБ

\begin{tabular}{|c|c|c|c|c|c|c|c|c|c|}
\hline $\begin{array}{l}\text { Номер } \\
\text { образца }\end{array}$ & $\begin{array}{c}\text { Содер- } \\
\text { жание } \\
\text { Nafion, } \\
\text { wt.\% }\end{array}$ & $\begin{array}{r}\text { Порис- } \\
\text { тость, \% }\end{array}$ & $\begin{array}{c}\text { Площадь } \\
\text { активной } \\
\mathrm{Pt}(\text { катод), } \\
\mathrm{cm}^{2} / \mathrm{g}\end{array}$ & $\begin{array}{c}\text { Загрузка Pt } \\
\text { (катод/анод), } \\
\mathrm{mg}\end{array}$ & $\begin{array}{c}\text { Толщина } \\
\text { (катод/анод), } \\
\mu \mathrm{m}\end{array}$ & \begin{tabular}{|c} 
Сопротив- \\
ление \\
мембраны \\
и контактов \\
$R_{H f}, \Omega$ \\
\end{tabular} & $\begin{array}{c}\text { Концентрация } \\
\text { центров гене- } \\
\text { рации воды } \\
C_{a c t} \cdot 10^{-18} \\
\mathrm{~cm}^{-1}\end{array}$ & $\begin{array}{c}\text { Ионное } \\
\text { сопротив- } \\
\text { ление } \\
\rho_{H^{+}}(\text {вах. }) \\
\Omega \cdot \mathrm{cm} \\
\end{array}$ & $\begin{array}{c}\text { Ионное } \\
\text { сопротив- } \\
\text { ление } \\
\rho_{H^{+}}(\text {имп.), } \\
\Omega \cdot \mathrm{cm} \\
\end{array}$ \\
\hline 72 & 10 & 77 & 14 & $0.04 / 0.02$ & $3.3 / 1.8$ & 0.20 & 4.1 & 7450 & 3940 \\
\hline 73 & 25 & 77 & 57 & $0.1 / 0.07$ & $14 / 7.7$ & 0.11 & 12 & 175 & 98 \\
\hline 67 & 40 & 68 & 100 & $0.1 / 0.08$ & $14 / 12$ & 0.11 & 20 & 107 & 220 \\
\hline 68 & 60 & 52 & 82 & $0.12 / 0.11$ & $14 / 14$ & 0.14 & 38 & 280 & 236 \\
\hline 74 & 80 & 12 & 20 & $0.12 / 0.09$ & $15 / 14$ & 0.79 & 3.9 & 1010 & 670 \\
\hline
\end{tabular}




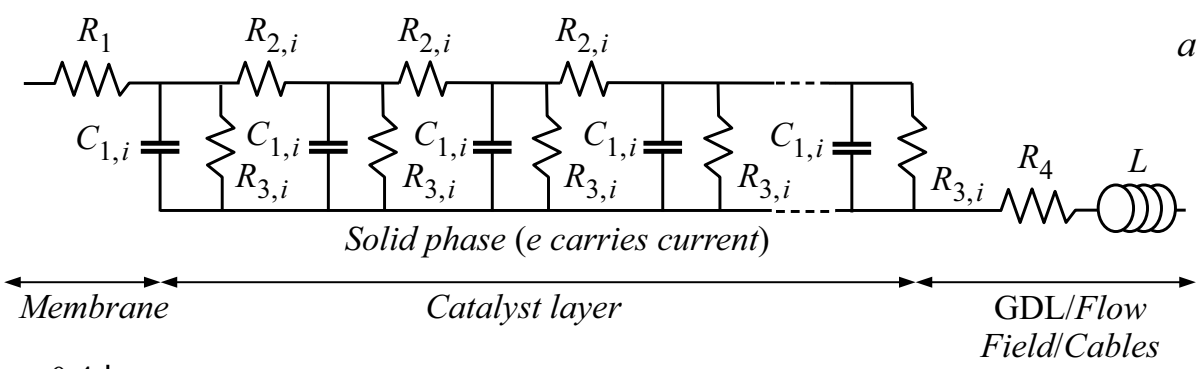

Pис. 1. $a-$ эквивалентная электрическая схема: $R_{1}-$ ионное сопротивление мембраны, $R_{2, i}-$ ионное сопротивление электрода, $R_{3, i}-$ сопротивление переноса заряда, $R_{4}-$ сопротивление контактов и кабелей, $C_{1, i}-$ емкость двойного слоя, $L-$ паразитная емкость ячейки и кабелей. $b-$ экспериментальные (темные символы) и модельные (программа ZView2.3) (светлые символы) высокочастотные области годографов импеданса для МЭБ № 67 (прямая - линейная экстраполяция) и № 74 с содержанием Nafion 40 и 80 wt.\% соответственно. Тангенс наклона линейной аппроксимации для МЭБ № 67 составляет $1.06\left(46^{\circ}\right)$. 
к напряжению разомкнутой цепи (поляризация 0-100 mV), амплитуде переменного напряжения $8 \mathrm{mV}$, сопротивлении переноса заряда $R_{c t}>80 \Omega$ в интервале частот $500 \mathrm{kHz}-1 \mathrm{~Hz}$.

По экспериментальным годографам электрохимического импеданса посредством программы ZView2.3 осуществлялась подгонка модельной кривой. В качестве подгоночных параметров использовались ионное сопротивление, сопротивление электрохимической реакции, емкость, сопротивления контактов и мембраны $R_{H f}$ (см. таблицу), „паразитная“ индуктивность ячейки и проводов оценивалась с помощью годографа импеданса. Сопротивление электрохимической реакции было существенно выше ионного сопротивления $\left(R_{c t}>80 \Omega\right)$.

При моделировании использовалась одномерная модель распределения подгоняемых параметров в электроде. При подгонке электрод условно разбивали вдоль толщины на десять равных частей, применяли стандартную эквивалентную схему [14] (рис. 1,a). Ионное сопротивление электрода вычисляли, суммируя сопротивления слоев.

Концентрацию центров генерации воды $\mathrm{C}_{a c t}\left(\mathrm{~cm}^{-1}\right)$ в МЭБ вычисляли, используя измеренную площадь электрохимической активной платины на катоде (месте выделения $\mathrm{H}_{2} \mathrm{O}$ ), приведенную ко всей толщине МЭБ.

В таблице сведены характеристики исследованных образцов. На рис. 1, $b$ приведены экспериментальные и модельные годографы электрохимического импеданса для двух образцов с различным содержанием Nafion. Из рисунка видно, что для образца с содержанием Nafion, близким к обычно используемому (40 wt.\%), годограф имеет форму, близкую к классической для однородного электрода, т.е. в высокочастотной области присутствует линейный участок с углом наклона $\sim 45^{\circ}$. Годограф образца с высоким содержанием Nafion (80 wt.\%) имеет уже искаженную форму, что свидетельствует о неоднородности характеристик электрода [15].

Анализ профилей ионного сопротивления МЭБ, полученных на основе моделирования годографов импеданса, приведенных на рис. 2, позволяет сделать следующие выводы. Ионное сопротивление катода для образцов № 67, 68, 73 с относительно большой концентрацией активных центров генерации воды, находящейся в интервале $(12-38) \cdot 10^{18} \mathrm{~cm}^{-1}$, имеет относительно невысокие значения, и распределение его по толщине электрода относительно равномерное. Для образцов № 72, 74 с малой концентрацией активных центров -

Письма в ЖТФ, 2018, том 44, вып. 23 


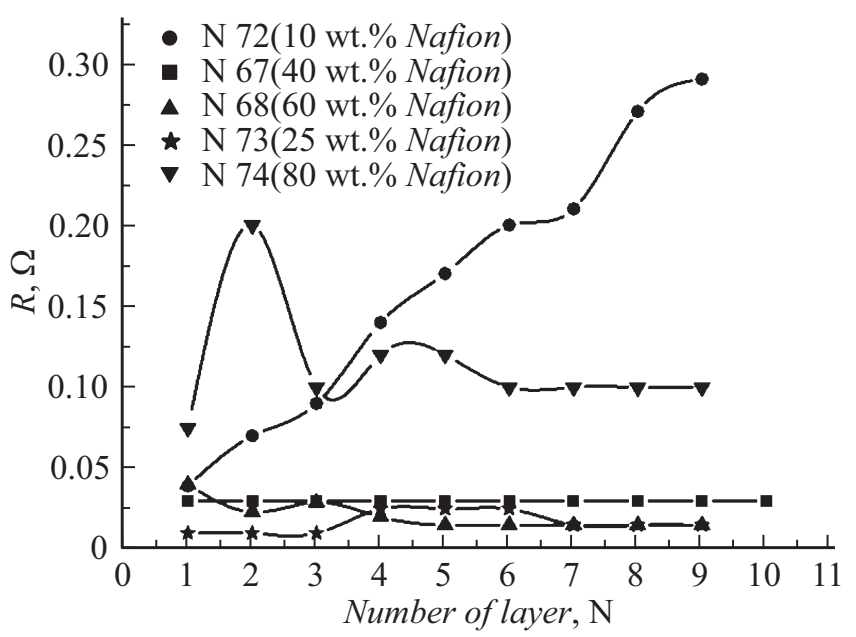

Рис. 2. Профили ионного сопротивления катода, полученные на основании результатов моделирования электрохимического импеданса для МЭБ с различным содержанием Nafion.

(3.9-4.1) $\cdot 10^{18} \mathrm{~cm}^{-1}$ - ионное сопротивление значительно выше и сильно неоднородно по толщине электрода. При этом для более пористого образца с меньшей толщиной электрода (№ 72) сопротивление сильно возрастает к границе с прикатодным пространством, тогда как для образца с малой пористостью (№ 74) ионное сопротивление увеличено у границы с мембраной. Это свидетельствует о том, что в первом случае происходит осушение внешнего слоя электрода, которое можно объяснить увеличенным вкладом конвекции в переносе воды с потоком кислорода в прикатодном пространстве.

Так как существующее некоторое различие (при сохранении общей тенденции) величин ионного сопротивления, измеренных двумя методами (см. таблицу и рис. 3), до конца неясно и требует отдельных исследований, для дальнейшего анализа был выбран апробированный метод, основанный на измерении ВАХ [18], позволяющий определять ионное сопротивление электрода.

Из вставки к рис. 3 видно, что удельное ионное сопротивление электродов, измеренное по ВАХ, имеет минимум при содержании Nafion в диапазоне 25-40wt.\%. При дальнейшем увеличении содер-

Письма в ЖТФ, 2018, том 44, вып. 23 


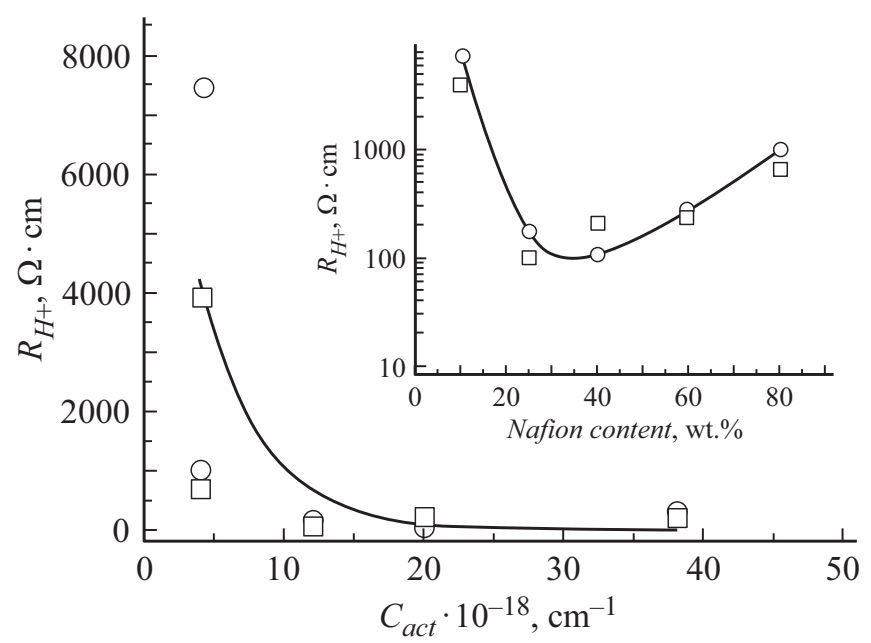

Рис. 3. Зависимости удельного ионного сопротивления электрода МЭБ от концентрации активных центров генерации воды и от содержания Nafion (на вставке) для величин, полученных на основе анализа данных ВАХ и моделирования годографа импеданса. Кружки - расчетные ВАХ, квадраты моделирование импеданса, линия - аппроксимация.

жания Nafion сопротивление увеличивается. На зависимости этого же сопротивления от концентрации активных центров генерации воды (электрохимически активных атомов платины) видно (рис. 3), что ионное сопротивление начинает резко возрастать, когда концентрация активных центров становится меньше $12 \cdot 10^{18} \mathrm{~cm}^{-1}$. Это соответствует образцам с содержанием Nafion 25-40 wt.\%. Наблюдаемые закономерности свидетельствуют о связи ионного сопротивления с концентрацией активных центров генерации воды. Данные рис. 2,3 показывают, что образцы с относительно небольшой концентрацией активных центров генерации воды имеют неоднородное ионное сопротивление по толщине электрода.

Показано, что экспериментально наблюдаемое увеличение ионного сопротивления связано с малой объемной долей центров генерации воды (частиц платины), производящих недостаточное ее количество для обеспечения полного увлажнения Nafion. Неоднородный концентрационный профиль воды в работающем мембранно-электродном блоке при

Письма в ЖТФ, 2018, том 44, вып. 23 
низком ее содержании может создавать соответствующий неоднородный профиль ионного сопротивления Nafion и приводить к увеличению ионного сопротивления.

Приведенные в работе результаты важны как для понимания фундаментальных процессов ионного транспорта в рассматриваемых электродных системах, так и с практической точки зрения при проектировании электродов и измерении их транспортных характеристик.

\section{Список литературы}

[1] Asmatulu R., Khan A., Adigoppula V.K., Hwang G. // Int. J. Energy Res. 2018. V. 42. P. $508-519$.

[2] Shetzline J.A., Creager S.E. // J. Electrochem. Soc. 2014. V. 161. P. H917-H923.

[3] Okumura M., Noda Z., Matsuda J., Tachikawa Y., Nishihara M., Lyth S.M., Hayashi A., Sasaki K. // J. Electrochem. Soc. 2017. V. 164. P. F928-F934.

[4] Xu F., Leclerc S., Stemmelen D., Perrin J.-K., Retournard A., Canet D. // J. Membrane Sci. 2017. V. 536. P. 116-122.

[5] Fathi H., Raoof A., Mansouri S.H. // J. Power Sources. 2017. V. 349. P. 57-67.

[6] Нечитайлов А.А., Глебова Н.В., Кошкина Д.В., Томасов А.А., Зеленина Н.К., Терукова Е.Е. // Письма в ЖТФ. 2013. Т. 39. В. 17. С. 17-26.

[7] Глебова Н.В., Нечитайлов А.А., Краснова А.О., Томасов А.А., Зеленина Н.К. // ЖПХ. 2015. Т. 88. В. 5. С. 726-731.

[8] PEM fuel cell electrocatalysts and catalyst layers / Ed. J. Zhang. Vancouver: Springer, 2008. $1137 \mathrm{p}$.

[9] Sone Y., Ekdunge P., Simonsson D. // J. Electrochem. Soc. 1996. V. 143. P. $1254-1259$.

[10] Matos B.R., Goulart C.A., Elisabete I., Santiago E.I., Muccillo R., Fonseca F.C. // Appl. Phys. Lett. 2014. V. 104. P. 091904.

[11] Нечитайлов А.А., Глебова Н.В., Краснова А.О., Томасов А.А., Зеленина Н.К. // ЖТФ. 2015. Т. 85. В. 11. С. 97-103.

[12] Liu L., Chen W., Li Y. // J. Membrane Sci. 2016. V. 504. P. 1-9.

[13] Saito M., Arimura N., Hayamizu K., Okada T. // J. Phys. Chem. B. 2004. V. 108. P. 16064-16070.

[14] Makharia R., Mathias M.F., Bakerb D.R. // J. Electrochem. Soc. 2005. V. 152. P. A970-A977.

[15] Gerteisen D. // J. Electrochem. Soc. 2015. V. 162. P. F1431-F1438.

[16] URL.http://www.nanotc.ru/index.php/producrions/87-cnm-taunit

[17] Litster S., McLean G. // J. Power Sources. 2004. V. 130. P. 61-76.

[18] Глебова Н.В., Краснова А.О., Томасов А.А., Зеленина Н.К., Нечитайлов А.А. // ЖТФ. 2017. Т. 87. В. 6. С. 880-883.

[19] Андроников Д.А., Зеленина Н.К., Терукова Е.Е., Томасов А.А. Способ активации мембранно-электродного блока. Патент № 2487442. Заявка № 2012107563 от 28.02 .2012 . 